\title{
APLIKASI TQM DALAM PENGELOLAAN PENDIDIKAN
}

\author{
Oleh : Drs Moh. Masnun, M.Pd
}

\begin{abstract}
Abstraksi
Di era globalisasi dan modernitas saat ini peningkatan mutu pendidikan menjadi masalah yang urgen. Pendidikan yang baik dan bermutu menjadi dasar pengembangan dan kemajuan. Oleh karena itu pengelola dan penyelenggara pendidikan harus merespon berbagai kebijakan pemerintah dan harapan masyarakat.

Pendidikan yang dikelola lembaga pendidikan merupakan amanah. Bagaimanapun kepercayaan itu harus dibayar dengan layanan pendidikan yang memberikan kepuasan kepada pelanggan. Kepuasan tersebut hanya dapat dicapai melalui penyelenggaraan pendidikan yang bermutu. Mutu yang benar-benar mampu memuaskan pelanggan adalah mutu yang secara teoritis nyaris tanpa cacad.

Tulisan ini menyajikan pembahasan tentang TQM yang meliputi pengertian landasan pemikiran, hambatan, dan strategi aplikasinya ke dalam pendidikan.
\end{abstract}

Kata Kunci : Pendidikan, Manajemen, Mutu, Total, Kepuasan, Pelanggan

\section{A. Pendahuluan}

Pada era kontemporer ini dunia pendidikan dikejutkan dengan adanya model pengelolaan pendidikan berbasis industri. Pendekatan model ini menuntut pengelola pendidikan untuk meningkatkan mutu pendidikan berdasarkan manajemen perusahaan. Penerapan manajemen mutu dalam pendidikan lebih popular dengan sebutan Total Quality Education (TQE). Dasar dari manajemen ini dikembangkan dari konsep Total Quality Management (TQM).

Strategi yang dikembangkan dalam penggunaan lembaga pendidikan memposisikan sebagai industri jasa. Yakni institusi yang memberikan pelayanan sesuai dengan apa yang diinginkan oleh pelanggan. Salah satu kunci yang terbukti mujarab dalam 
mempertahankan eksistensi sebuah organisasi adalah komitmen kepada kepuasan pelanggan dengan memberikan jaminan kualitas produk dan jasa yang bermutu.

Membangun kualitas sungguh enak didengar tetapi sulit dilakukan. Selama bertahun-tahun pakar manajemen telah secara terus menerus mengembangan berbagai strategi membangun mutu. Diantara pakar tersebut adalah W. Edwards Deming, seorang ahli statistic ternama dari Amerika yang menyakini bahwa “......Untuk membangun sistem kualitas modern diperlukan tranformasi manajemen menuju kondisi perbaikan terus menerus....."

TQM memperkenalkan pengembangan proses, produk dan pelayanan sebuah organisasi secara sistematik dan berkesinambungan. Pendekatan ini berusaha melibatkan semua pihak terkait dan memastikan bahwa pengalaman dan ide-ide mereka memiliki sumbangan dalam pengembangan mutu.

Pengelamanan berbagai organisasi pendidikan menunjukkan bahwa TQM dapat diterapkan ke dalam sistem pendidikan. Oleh sebab itu ketika banyak pendidikan yang merasa prihatin dengan kualitas pendidikan nasional, penerapan TQM dalam manajemen pendidikan perlu dijadikan alternatif emecahan masalah.

Tulisan ini diharapkan dapat menjadi pembuka cakrawala pemikiran para menajer pendidikan agar memahami tentang TQM dengan baik. Dengan pemahaman tersebut mereka diharapkan mampu menerapkan TQM dalam mengelola satuan pendidikan untuk mencapai keunggulan yang berdaya saing. 


\section{B. Pembahasan}

\section{Pengertian Mutu}

Telah dibuktikan pula sejak beberapa dasawarsa belakangan ini bahwa mutu atau segalanya yang menyangkut mutu adalah konsep yang paling manjur dalam rnenghadapi tantangan-tantangan yang tak kunjung habis dan justru bertambah kompleks. Konsep mutu ini telah pula dipakai di sekolah-sekolah di manca Negara juga di Indonesia dengan rnenghasilkan peningkatan pundidikan yang cukup bermakna bagi siswa, orag tua, industri dan masyarakat luas di sekelilingnya. Tingkat layanan dan pendidikan berpengaruh penting pada perkembangan kesadaran masyarakat akan mutu. Konsep mutu telah berkembang sejalan dengan perkembangan masyarakatr dan dari sisi mana memandangnya. Beberapa definisi mutu yang berkembang dikenal sebagai berikut:

Juran M. Juran (1982) mengemukakan bahwa "Quality is fitness for use".

Edward Sallis (1993) mengemukakan bahwa "Quality is fitness purpose”

Faangen \& Long (1985) mengernukakan bahwa "Quality is total composite product and sservice of characters of marketing, engineering, manufacture and maintenance through which the product and service in use will meet the expectation by customer".

Wadsworth et.al sebagaimana dikutip oleh Adviso (1998: 1) yaitu "Quality is the totality of features and characteristics of product or service that bear on its ability to satisfy given needs".

Gaspersz (2002) menjelaskan bahwa mutu memiiki banyak definisi yang berbeda dan bervariasi, dan konvensional sampai modern. Definisi konvensional mendefinisi-kan karakteristik langsung dan suatu 
produk, sedangkan definisi modern menjelaskan bahwa mutu adalah segala sesuatu yang mampu memenuhi keinginan atau kebutuhan pelanggan. Narnun, konsep dasar mutu adalah segala sesuatu yang dapat diperbaiki karena pada dasarnya tidak ada proses yang sempurna.

Definisi mutu menurut Arcaro (2006) adalah sebuah derajat variasi yang terduga standar yang digunakan dan memiiki ketergantungan pàda biaya yang rendah. Menurut Daming dalam Arcaro, mutu berarti pemecahan untuk mencapai penyempurnaan terusmenerus. Dalam dunia pendidikan, menurut Daming, yang dapat diterapkan dalam dunia pendidikan adalah (1) anggota dewan sekolah dan administrator harus menetapkan tujuan pendidikan; menekankan pada upaya kegagalan pada siswa; (3) menggunakan metode kontrol statistik untuk membantu memperbaiki outcome siswa dan administratif.

Mencermati berbagai pengertian tentang mutu sebagaimana telah diuraikan, tak dapat dipungkiri bahwa agar semua pihak yang berkepentingan, penjual dan pelanggan, memiliki ukuran yang sama tentang mutu suatu produk atau jasa, perlu ditetapkan standar mutu. Dengan demikian dapat dinyatakan bahwa mutu adalah bertemunya hasil dengan standar. Sebagai contoh dalam konteks pendidikan, nilai batas kelulusan merupakan standar mutu minimal yang harus dicapai oleh siswa agar yang bersangkutan dapat dikategorikan bermutu. Contoh lain seorang mahasiswa pendidikan S1 (Sarjana) menilai bahwa layanan yang diberikan oleh sebuah fakultas bermutu jika yang bersangkutan dapat menyelesaikan pendidikannya secara tepat waktu, misalnya 8 (delapan) semester. Dalam hal ini standar mutunya adalah waktu penyelesaian perkuliahan yaitu 8 (delapan) semester. 
Dan uraian di atas dapat dinyatakan bahwa mutu adalah bertemunya penampilan atau kinerja atau performance dengan harapan atau expectation. Secara kuantitatif, mutu dapat dituliskan dalam bentuk rumus berikut ini;

$\mathrm{Q}=\mathrm{P} / \mathrm{E}$

Dengan mana :

$\mathrm{Q}=$ Quality atau mutu

$\mathrm{P}=$ Performance atau penampilan atau kinerja atau capaian

$\mathrm{E}=$ Expectation atau harapan atau standar.

Aplikasi rumus ini akan menghasilkan 3 (tiga) kemungkinan mutu capaian sebagai berikut: § Jika $\mathrm{P}<\mathrm{E}$ maka Q -1 yang berarti unsatisfaction atau tidak bermutu dan mengecewakan pelanggan. Contoh kasus dalam pendidikan; kekecewaan mahasiswa karena dosen yang datang tidak tepat waktu. $\S$ Jika $\mathrm{P}=\mathrm{E}$ maka $\mathrm{Q}=1$ yang berarti satisfaction atau bermutu yang memuaskan pelanggan. Contoh kasus dalam pendidikan; kepuasan mahasiswa karena dosen memulai dan mengakhiri perkuliahan tepat waktu. $\quad$ J Jika P > E maka Q> 1 yang berarti delight atau menggembirakan atau memberikan rasa dihargai pada diri pelanggan.Contoh kasus dalam pendidikan; mahasiswa yang merasa sangat gembira karena dosen memulai dan mengakhir perkualiahan secara tepat waktu dan telah menyediakan handout sehingga waktu perkualiahan termanfaatkan secara efeektif dan efisien.

\section{Manajemen Mutu}

Dalam manajemen mutu dikenal 3 (tiga) teknik atau pendekatan yaitu; pengendalian mutu atau quality control atau QC, penjaminan mutu atau quality assurance atau QA, dan TQM (Sallis, 2006: 58). Pengendalian mutu bersifat inspeksi yang dilakukan untuk memeriksa 
kecacadan produk. Berbeda dengan itu, penjaminan mutu dilakukan untuk mencegah terjadinya kecacadan produk sejak awal proses hingga proses berlangsung. Seperti dilukiskan dalam Gambar 4, pengendalian mutu adalah pengelolaan mutu pada tahapan keluaran, sedangkan penjaminan mutu adalah upaya pengelolaan kualitas yang terfokus pada input dan proses.

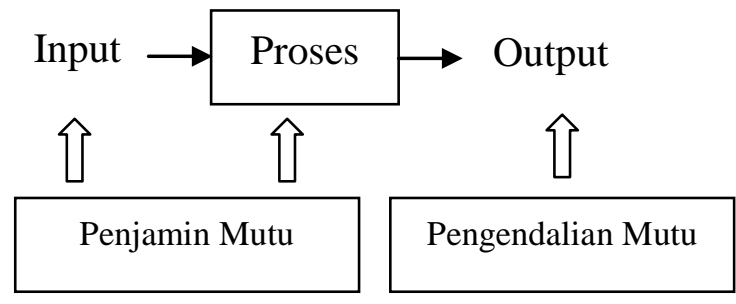

Gambar 4 :

Tahapan Dalam Manajemen Mutu

TQM sebagai pendekatan terkini lebih komprehsnif. Pendekatan ini sebagaimana dikatakan oleh Sallis “... merupakan perluasan dan pengembangan dari penjaminan mutu. TQM adalah tentang usaha menciptakan sebuah kultur mutu, yang mendorong semua anggota stafnya untuk memuaskan pelanggan." (Sallis: 59).

\section{Menata Mutu}

Menata mutu bagaikan menyusun keberadaan rumah yang berantakan dan tak teratur berserakan, kemudian kita susun satu persatu sesuai tempat dan kegunaannya. Jika ini disusun oleh orang yang ahli, rumah tersebut akan menjadi teratur dan indah yang enak dipandang. Dalam dunia pendidikan, menata mutu bisa lebih sulit dari itu semua karena bersifat kompleks. Secara kelembagaan, menata lembaga pendidikan yang bermutu sering mengadopsi dan terinspirasi dari keberhasilan dunia industri atau bisnis sehingga usaha menciptakan lembaga pendidikan yang bermutu tidak lepas dan aplikasi bidang 
tersebut. Oleh karenanya, modelnya disesuaikan dan diambil kesamaan paradigma keduanya antara pendidikan dan dunia industri, khususnya dalamn hal jasa, yaitu ilmu pengetahuan, keterampilan, sikap, perilaku, moralitas, dan seterusnya.

Jika dilihat dari teori sikius kehidupan, lembaga pendidikan akan eksis selama ia dapat meraih tujuan yang bermanfaat dan akan mengalami perubahan yang konstan. Dalam bahasa biologi, lembaga pendidikan akan mengalami siklus kehidupan (life cycle), yang memiiki empat tahapan, yaitu formasi; pertumbuhan; kedewasaan; penurunan (mati) kejatuhan, atau pembaruan; revitalisasi. Oleh karenanya, setiap tahapan memiliki tantangan tersendiri dan kegagalan menghadapinya mengakibatkan bencana bagi institusi atau lembaga pendidikan sebab pada setiap tahapannya ia harus berubah, beradaptasi, dan berkembang.

Sallis (2010) menjelaskan bahwa TQM dengan segenap perencanaan strategis jangka panjang dan pelibatan karyawan secara menyeluruh memiliki strategi tersendiri dalam menghadapi tantangan dan perubahan setiap fase atau tahapannya.

Fase pertama adalah siklus kelahiran atau formasi institusi. Pada fase pertama ini, lembaga pendidikan yang baru berdiri harus memiliki hal-hal berikut.
a. Memiliki visi dan misi jelas.
b. Pengakuan dan dukungan.
c. Menemukan bentuk di pasaran dan pelanggan.
d. Membangun bisnis pelanggan dan memastikan tersebut dapat memenuhi kebutuhan pelanggan.
e. Berani menjamin dan mengambil risiko. 
Fase kedua adalah pertumbuhan dan perkembangan. Dalam fase ini, lembaga akan mengalami sebagai benikut.

a. Tantangan pelayanan yang optimal.

b. Membuat hubungan dan mempenluas pelanggan.

c. Komunikasi yang optimal dan tepat dalam etos kerja dengan karyawan.

d. Mengadakan pelatihan.

e. Menghadapi tantangan-tantangan baru.

f. Harus yakin dan optimis untuk terus berkembang.

g. Mengatasi tuntutan peningkatan pelayanan.

Kesalahan dalam sistem manajemen, ketidakmampuan mendelegasikan, serta pengangkatan karyawan yang tidak memiliki etos kerja yang tepat adalah kegagalan.

Ada beberapa bahaya besar dalam fase perkembangan, yaitu ketika membutuhkan aturan dan prosedur, biasanya menggiring pada lembaga atau birokrasi yang kurang bermanfaat, yang akan melumpuhkan visi dan misi organisasi yang sesungguhnya, ada risiko mengubah kecenderungan pasar menuju produk.

Jika digambarkan, fase kehidupan dalam lembaga atau organisasi adalah sebagai berikut.

SIKLUS KEHIDUPAN ORGANISASI ATAU LEMBAGA

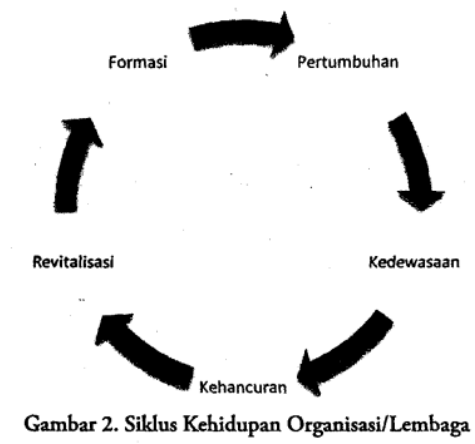


Ketika membaca model TQM dalam pendidikan, ternyata Sallis juga menjawab tidak ada bentuk organisasi yang baku dalam TQM meskipun ada beberapa struktur yang lebih tepat diaplikasikan dibandingkan yang lain. Struktur yang digunakan harus tepat dan mempermudah proses TQM. Lembaga atau institusi pendidikan yang mengembangkan TQM harus menghilangkan sistem hierarki dan mengganti dengan sistem yang lebih sejajar hubungan interinstitusional. Jadi, model yang tepat dalam TQM adalah bentuk yang sederhana, ramping, dan dibangun dalam tim kerja yang kuat.

Hierarki yang tinggi dalam sekolah dan lapisan manjemen yang berlebihan dapat memunculkan kesulitan dalam ruang kelas sehingga staf tidak dapat menjalankan pekerjaannya secara efektif. Jadi, konsep TQM menekankan kerja tim, pengembangan, dan penguatan tim kerja sehingga mempermudah dan meringankan kinerja manajer menengah.

Manajemen menengah menjadi pemimpin dalam pengendalian mutu dan berperan mendorong tim dan membantu perkembangan mereka sebab jika tidak, fungsinya dapat menurun drastis. Sementara, tim yang memiliki otonomi terlalu luas dapat mengakibatkan gerak mereka tidak terkoordinasi dan tidak efektif sehingga kerja tim harus diatur dengan manajemen sederhana yang efektif yang harus mampu memahami visi dan kebijakan lembaga. Inilah istimewanya TQM yang juga menekankan pentingnya visi.

Gambaran model lembaga TQM dan instimsi biasa adalah sebagai berikut. 


\section{MODEL LEMBAGA TQM DAN INSTITUSI BIASA}

\begin{tabular}{|c|c|}
\hline Institusi Mutu & Institusi Biasa \\
\hline Fokus pada pelanggan & Fokus pada kebutuhan internal. \\
\hline Fokus pada pencegahan masalah & Fokus pada deteksi masalah. \\
\hline Investasi sumber daya & $\begin{array}{l}\text { Pendekatan dalam pengembangan karyawan } \\
\text { tidak sistematis. }\end{array}$ \\
\hline Memiliki strategi mutu & Kekurangan visi strategi mutu. \\
\hline $\begin{array}{l}\text { Menyikapi komplain sebagai peluang untuk } \\
\text { belajar lebih baik. }\end{array}$ & Menyikapi komplain sebagai gangguan. \\
\hline Mendefinisikan karakteristik mutu & $\begin{array}{l}\text { Sama sekali tidak memiliki standar mutu yang } \\
\text { jelas. }\end{array}$ \\
\hline Memiliki kebijakan dan rencana mutu & Tidak memiliki rencana mutu \\
\hline Manajemen senior memimpin mutu & $\begin{array}{l}\text { Peran manajemen dipandang sebagai salah } \\
\text { satu bentuk kekangan. }\end{array}$ \\
\hline $\begin{array}{l}\text { Proses perbaikan mutu melibatkan setiap } \\
\text { orang. }\end{array}$ & $\begin{array}{l}\text { Hanya melibatkan tim manajemen dalah hal } \\
\text { apa pun. }\end{array}$ \\
\hline $\begin{array}{l}\text { Memiliki fasilitator mutu dalam mendorong } \\
\text { proses. }\end{array}$ & Tidak memiliki fasilitator mutu. \\
\hline $\begin{array}{l}\text { Karyawan dianggap memiliki peluang untuk } \\
\text { menciptakan mutu. Kreativitas adalah hal yang } \\
\text { penting. }\end{array}$ & $\begin{array}{l}\text { Prosedur dan aturan yang baku adalah hal } \\
\text { yang penting. }\end{array}$ \\
\hline $\begin{array}{l}\text { Memiliki aturan dan tanggung jawab yang } \\
\text { jelas. }\end{array}$ & $\begin{array}{l}\text { Tidak memiliki aturan dan tanggung jawab } \\
\text { yang jelas. }\end{array}$ \\
\hline Memiliki strategi evaluasi yang jelas. & $\begin{array}{l}\text { Tidak memiliki strategi evaluasi yang jelas } \\
\text { dan sistematis. }\end{array}$ \\
\hline $\begin{array}{l}\text { Melihat mutu sebagai cara meningkatkan } \\
\text { kepuasan pelanggan. }\end{array}$ & $\begin{array}{l}\text { Melihat mutu sebagai cara untuk menghemat } \\
\text { biaya. }\end{array}$ \\
\hline Rencana jangka panjang. & Rencana jangka pendek. \\
\hline Mutu dipandang sebagai bagian dan budaya. & $\begin{array}{l}\text { Memandang mutu sebagal inisiatif yang } \\
\text { mengganggu. }\end{array}$ \\
\hline $\begin{array}{l}\text { Meningkatkan mutu berada dalam garis } \\
\text { strategi imperatifnya sendiri. }\end{array}$ & $\begin{array}{l}\text { Memeriksa mutu dengan tujuan untuk } \\
\text { memenuhi tuntutan agen eksternal. }\end{array}$ \\
\hline Memiliki misi khusus. & Tidak memiliki misi khusus. \\
\hline Memperlakukan kolega sebagai pelanggan. & Memiliki budaya hierarkis. \\
\hline
\end{tabular}

Untuk menguji apakah sebuah lembaga sekolah/madrasah bermutu atau tidak, dapat dibuatkañ tabel pengendalian uji mutu, antara lain model Sallis berikut mi. 
Skor 1: sangat jelek

Skor 2: jelek

Skor 3: cukup

Skor 4: baik

Skor 5: baik sekali

\section{PENGENDALIAN MUTU \\ DALAM TQM}

\begin{tabular}{|c|c|c|c|c|c|c|}
\hline \multirow{2}{*}{\multicolumn{2}{|c|}{ Kegiatan TQM }} & \multicolumn{5}{|c|}{ Skor } \\
\hline & & 1 & 2 & 3 & 4 & 5 \\
\hline \multicolumn{7}{|c|}{ A. Akses } \\
\hline \multicolumn{7}{|c|}{ Hubungan dengan pelanggan } \\
\hline 1 & Hubungan awal yang jelas dengan pelanggan. & & & & & \\
\hline 2 & Penerimaan yang baik. & & & & & \\
\hline 3 & Respons telepon yang cepat. & & & & & \\
\hline 4 & Petunjuk dan pedoman yang siap sedia. & & & & & \\
\hline 5 & $\begin{array}{l}\text { Survel tentang respons ngunjung terhadap sambutan } \\
\text { yang mereka terima. }\end{array}$ & & & & & \\
\hline 6 & Tanda-tanda petunjuk yang jelas. & & & & & \\
\hline \multicolumn{2}{|c|}{ Akses yang terbuka } & 1 & 2 & 3 & 4 & 5 \\
\hline 1 & $\begin{array}{l}\text { Jalan landai dan lift khusus untuk para penderita } \\
\text { tunadaksa. }\end{array}$ & & & & & \\
\hline 2 & $\begin{array}{l}\text { Bahasa awam yang digunakan dalam tanda- tanda } \\
\text { petunjuk dan literatur. }\end{array}$ & & & & & \\
\hline
\end{tabular}

\begin{tabular}{|l|l|l|l|l|l|l|}
\hline \hline B. Layanan bagi Pelanggan & $\mathbf{1}$ & $\mathbf{2}$ & $\mathbf{3}$ & $\mathbf{4}$ & $\mathbf{5}$ \\
\hline Petunjuk dan bimbingan & Layanan informasi dan bimbingan yang slap sedia. & & & & & \\
\hline 1 & Bimbingan masuk yang tepat bagi calon pelajar. & & & & & \\
\hline 2 & Petunjuk lanjut yang siap sedia. & & & & & \\
\hline 3 & Petunjuk karier yang siap sedia. & & & & & \\
\hline 4 & $\begin{array}{l}\text { Kesejahteraan dan koriseling pelajar yang mudah } \\
\text { didapat. }\end{array}$ & & & & & \\
\hline 5 & $\begin{array}{l}\text { Pcrpustakaan dan pusat sumber daya yang memadai. } \\
\text { Sumber daya dalam proses belajar }\end{array}$ & & & & & \\
\hline 1 & Sumber daya belajar yang terbuka. & & & & & \\
\hline 2 & Fasilitas komputer yang baik. & & & & & \\
\hline 3 & Fasilitas umum & $\mathbf{1}$ & $\mathbf{2}$ & $\mathbf{3}$ & $\mathbf{4}$ & $\mathbf{5}$ \\
\hline
\end{tabular}




\begin{tabular}{|c|c|c|c|c|c|c|}
\hline 1 & Fasilitas kantin yang siap dan balk. & & & & & \\
\hline 2 & Fasilitas olahraga yang memadai. & & & & & \\
\hline 3 & Fasilitas relaksasi yang baik dan memadai. & & & & & \\
\hline 4 & $\begin{array}{l}\text { Kesempatan bagi pelajar untuk mengorganisasi } \\
\text { aktivitasnya. }\end{array}$ & & & & & \\
\hline \multicolumn{7}{|c|}{ C. Kepemimpinan } \\
\hline \multicolumn{2}{|c|}{ Kepala Sekolah } & $\mathbf{1}$ & 2 & 3 & 4 & 5 \\
\hline 1 & $\begin{array}{l}\text { Kepala sekolah yang memiliki dan menyebarkan visi } \\
\text { yang jelas. }\end{array}$ & & & & & \\
\hline 2 & Kepala sekolah yang menjalankan tugas. & & & & & \\
\hline 3 & Kepala sekolah yang mengenal staf & & & & & \\
\hline 4 & Kepala sekolah yang mengenal pelajar. & & & & & \\
\hline 5 & $\begin{array}{l}\text { Kepala sekolah yang menjalankan kepemimpinan } \\
\text { yang baik. }\end{array}$ & & & & & \\
\hline 6 & $\begin{array}{l}\text { Kepala sekolah yang menempatkan mutu sebagai } \\
\text { prioritas. }\end{array}$ & & & & & \\
\hline \multicolumn{2}{|c|}{ Nilai-nilai } & 1 & 2 & 3 & 4 & 5 \\
\hline 1 & Misi yang jelas dan bisa dipahami. & & & & & \\
\hline 2 & Kebijakan yang memberikan kesempatan yang sama. & & & & & \\
\hline
\end{tabular}

\begin{tabular}{|l|l|l|l|l|l|l|}
\hline 3 & Staf dan pelajar memahami etos sekolahnya. & & & & \\
\hline 4 & Komitmen yang kuat terhadap kebutuhan komunitas. & & & & \multicolumn{2}{l|}{} \\
\hline \multicolumn{2}{|l|}{ D. Lingkungan dan Sumber Daya Fisik } & $\mathbf{1}$ & $\mathbf{2}$ & $\mathbf{3}$ & $\mathbf{4}$ & $\mathbf{5}$ \\
\hline \multicolumn{2}{|l|}{ Bangunan, ruang kelas dan ruang lokakarya } & & & & & \\
\hline 1 & Bersih dan atraktif. & & & & & \\
\hline 2 & Sesuai dengan tujuan. & & & & & \\
\hline 3 & $\begin{array}{l}\text { Enak dipandang, nyaman, dan membantu proses } \\
\text { belajar mengajar. }\end{array}$ & & & & & \\
\hline Lingkungan belajar yang mendukung & Tata letak ruang yang menarik bagi siswa & & & $\mathbf{3}$ & $\mathbf{4}$ & $\mathbf{5}$ \\
\hline 1 & $\begin{array}{l}\text { Lingkungan belajar yang terencana dan terorganisir } \\
\text { dengan baik. }\end{array}$ & & & & & \\
\hline 2 & & & & & \\
\hline Kesehatan dan keselamatan & Pelajar terjaga dan bentuk kecelakaan. & & & & & \\
\hline 1 & Kebijakan kesehatan dan keselamatan yang diawasi & & & & & \\
\hline 2
\end{tabular}




\begin{tabular}{|c|c|c|c|c|c|c|}
\hline & dengan baik. & & & & & \\
\hline \multicolumn{2}{|c|}{ Kontrol dan Alokasi Sumber Daya } & 1 & 2 & 3 & 4 & 5 \\
\hline 1 & Kontrol sumber daya yang efektif. & & & & & \\
\hline 2 & Sumber daya terkontrol oleh yang menggunakannya. & & & & & \\
\hline \multicolumn{7}{|c|}{ D. Pembelajaran Efektif } \\
\hline \multicolumn{2}{|c|}{ Ketepatan Metode Pembelajaran } & 1 & 2 & 3 & 4 & 5 \\
\hline 1 & $\begin{array}{l}\text { Strategi pembelajaran dan pengajaran yang sesuai } \\
\text { dengan tujuan. }\end{array}$ & & & & & \\
\hline 2 & Variasi model pembelajaran baik dan menarik. & & & & & \\
\hline 3 & $\begin{array}{l}\text { Strategi pembelajaran dan pengajaran yang sesuai } \\
\text { dengan kriteria objektif. }\end{array}$ & & & & & \\
\hline 4 & $\begin{array}{l}\text { Strategi pembelajaran dan pengajaran yang sesuai } \\
\text { dengan respons pelajar. }\end{array}$ & & & & & \\
\hline 5 & Pembelajaran yang bersiht fokus pada pelajar. & & & & & \\
\hline 6 & $\begin{array}{l}\text { Pelajar ikut bertanggung jawab terhadap proses } \\
\text { belajar mereka. }\end{array}$ & & & & & \\
\hline 7 & Mengutamakan pembelajaran melalui skala prioritas. & & & & & \\
\hline 8 & $\begin{array}{l}\text { Metode evaluasi digunakan untuk mengetahui } \\
\text { respons pelanggan. }\end{array}$ & & & & & \\
\hline 9 & Tujuan akhir yang baik dapat diraih oleh para pelajar. & & & & & \\
\hline \multicolumn{2}{|c|}{ Ketepatan Portofolio Pembelajaran } & 1 & 2 & 3 & 4 & 5 \\
\hline 1 & Ketepatan portofolio dengan kebutuhan pelajar. & & & & & \\
\hline 2 & Materi program yang relevan dan modern. & & & & & \\
\hline 3 & $\begin{array}{l}\text { Respons yang cepat terhadap pengembangan } \\
\text { program baru. }\end{array}$ & & & & & \\
\hline 4 & Evaluasi klien terhadap relevansi penawaran. & & & & & \\
\hline 5 & $\begin{array}{l}\text { Penyampaian program dengan baik terhadap pemilik } \\
\text { lapangan kerja. }\end{array}$ & & & & & \\
\hline \multicolumn{2}{|c|}{ Pengawasan dan evaluasi } & 1 & 2 & 3 & 4 & 5 \\
\hline 1 & Umpan balik dan pelajar secara berkala. & & & & & \\
\hline 2 & Umpan balik dan pelanggan lain secara berkala. & & & & & \\
\hline 3 & $\begin{array}{l}\text { Kuesioner pelajar dan komunitas yang digunakan } \\
\text { secara tepat. }\end{array}$ & & & & & \\
\hline 4 & $\begin{array}{l}\text { Sistem formal institusi untuk tinjauan ulang dan } \\
\text { evaluasi. }\end{array}$ & & & & & \\
\hline
\end{tabular}




\begin{tabular}{|c|c|c|c|c|c|c|}
\hline 5 & $\begin{array}{l}\text { Umpan balik digunakan sebagai dasar untuk } \\
\text { membuat kebijakan. }\end{array}$ & & & & & \\
\hline \multicolumn{7}{|c|}{ E. Pelajar } \\
\hline \multicolumn{2}{|c|}{ Kepentingan Pelajar } & 1 & 2 & 3 & 4 & 5 \\
\hline 1 & Tanda dan petunjuk yang jelas. & & & & & \\
\hline 2 & Toilet yang bersih dan baik. & & & & & \\
\hline 3 & Buku panduan dan pedoman yang siap. & & & & & \\
\hline 4 & Staf sangat komunikatif dengan pelajar. & & & & & \\
\hline 5 & Sama sekali tidak ada kendala yang dibuat-buat. & & & & & \\
\hline 6 & Layanan pelajar yang baik. & & & & & \\
\hline 7 & Transportasi yang baik. & & & & & \\
\hline 8 & $\begin{array}{l}\text { Fasilitas rekreasi dan olahraga yang tersedia dan } \\
\text { baik. }\end{array}$ & & & & & \\
\hline \multicolumn{2}{|c|}{ Kepuasan Pelajar } & $\mathbf{1}$ & 2 & 3 & 4 & 5 \\
\hline 1 & Laporan yang baik tentang staf dan pelajar & & & & & \\
\hline 2 & $\begin{array}{l}\text { Kegembiraan dan kepuasan pelajar dibuktikan } \\
\text { melalui survei dan kuisioner. }\end{array}$ & & & & & \\
\hline 3 & Pelajar merasa bangga terhadap tugas mereka. & & & & & \\
\hline 4 & Pelajar selalu mendapat informasi. & & & & & \\
\hline 5 & Pandangan pelajar selalu terdata & & & & & \\
\hline \multicolumn{7}{|c|}{ F. Staf } \\
\hline \multicolumn{2}{|c|}{ Sikap dan Motivasi } & 1 & 2 & 3 & 4 & 5 \\
\hline 1 & Berkomitmen dan berpengetahuan. & & & & & \\
\hline 2 & Berfokus pada pelajar. & & & & & \\
\hline 3 & Bertanggung jawab terhadap mutu & & & & & \\
\hline 4 & Merasa bangga terhadap kerja mereka. & & & & & \\
\hline 5 & Selalu merasa senang & & & & & \\
\hline 6 & Merespons kebutuhan individu. & & & & & \\
\hline \multicolumn{2}{|c|}{ Tim Kerja } & & & & & \\
\hline 1 & Berkomitmen terhadap tim dan kerja tim. & & & & & \\
\hline 2 & Terlatih dalam keterampilan. & & & & & \\
\hline 3 & Memiliki kemampuan kerja tim yang kuat. & & & & & \\
\hline 4 & Memiiki ide yang jelas tentang batas otoritas. & & & & & \\
\hline 5 & Memiliki sumber daya yang mendukung mutu. & & & & & \\
\hline
\end{tabular}




\begin{tabular}{|c|c|c|c|c|c|c|}
\hline 6 & $\begin{array}{l}\text { Menghargai dan mendukung praktik-praktik kerja } \\
\text { yang baik. }\end{array}$ & & & & & \\
\hline 7 & Berkonsultasi tentang kebijakan secara teratur. & & & & & \\
\hline \multicolumn{2}{|c|}{ Pengembangan Staf } & 1 & 2 & 3 & 4 & 5 \\
\hline 1 & Institusi berkomitmen terhadap pengembangan staf. & & & & & \\
\hline 2 & $\begin{array}{l}\text { Pengembangan staf bersifat proaktif dan secara jelas } \\
\text { menegaskan kebutuhan institusi. }\end{array}$ & & & & & \\
\hline 3 & $\begin{array}{l}\text { Pengembangan staf memiliki tinjauan ulang terhadap } \\
\text { kebutuhan individu. }\end{array}$ & & & & & \\
\hline 4 & $\begin{array}{l}\text { Pengembangan staf mendapatkan sumber daya yang } \\
\text { cukup. }\end{array}$ & & & & & \\
\hline 5 & $\begin{array}{l}\text { Pengembangan staf merupakan bagian dan prioritas } \\
\text { institusi. }\end{array}$ & & & & & \\
\hline 6 & Pengembangan staf mencakup semua staf & & & & & \\
\hline 7 & Pengambangan stafu ntuk TQM. & & & & & \\
\hline \multicolumn{2}{|c|}{ Fasilitas Staf } & 1 & 2 & 3 & 4 & 5 \\
\hline 1 & Ruang kerja yang baik & & & & & \\
\hline 2 & Peralatan dan fasilitas yang tepat dan memadai. & & & & & \\
\hline 3 & $\begin{array}{l}\text { Kesempatan untuk melakukan diskusi dan debat } \\
\text { profesional. }\end{array}$ & & & & & \\
\hline \multicolumn{7}{|c|}{ G. Relasi Eksternal } \\
\hline \multicolumn{2}{|c|}{ Pemasaran } & 1 & 2 & 3 & 4 & 5 \\
\hline 1 & Strategi pemasaran yang logis. & & & & & \\
\hline 2 & Riset pasar & & & & & \\
\hline 3 & Mencari pandangan positif para pelanggan. & & & & & \\
\hline 4 & $\begin{array}{l}\text { Penyebaran kuesioner bagi para pelajar dan } \\
\text { para pemimpin lapangan kerja. }\end{array}$ & & & & & \\
\hline \multicolumn{2}{|c|}{ Komunitas } & 1 & 2 & 3 & 4 & 5 \\
\hline 1 & Hubungan baik dengan komunitas yang relevan. & & & & & \\
\hline 2 & Pandangan komunitas dimanfaatkan secara berkala. & & & & & \\
\hline 3 & $\begin{array}{l}\text { Hubungan kuat dengan rekanan pendidikan atau } \\
\text { rekanan bisnis. }\end{array}$ & & & & & \\
\hline \multicolumn{7}{|c|}{ H. Keroganisasian } \\
\hline \multicolumn{2}{|c|}{ Perencanaan Strategis } & $\mathbf{1}$ & 2 & 3 & 4 & 5 \\
\hline
\end{tabular}




\begin{tabular}{|c|c|c|c|c|c|c|}
\hline 1 & Institusi memiliki tujuan dan cita-cita yang luas. & & & & & \\
\hline 2 & $\begin{array}{l}\text { Staf di level } \\
\text { menyadari } \\
\text { institusi. }\end{array}$ & & & & & \\
\hline 3 & Institusi memiliki perencanaan strategis yang tertulis. & & & & & \\
\hline 4 & $\begin{array}{l}\text { Perencanaan mengindentifikasi cara staf agar dapat } \\
\text { memberikan konstribusi } \\
\text { kesuksesan. }\end{array}$ & & & & & \\
\hline \multicolumn{2}{|c|}{ Kultur Organisasi } & 1 & 2 & 3 & 4 & 5 \\
\hline 1 & Struktur yang sederhana dan ramping & & & & & \\
\hline 2 & Otoritas didelegasikan & & & & & \\
\hline 3 & Perubahan merupakan bagian kultur & & & & & \\
\hline 4 & Statemen umum tentang pengarahan & & & & & \\
\hline 5 & $\begin{array}{l}\text { Komitmen yang kuat untuk melakukan evaluasi dan } \\
\text { tinjauan ulang }\end{array}$ & & & & & \\
\hline 6 & Didasarkan pada kerja tim & & & & & \\
\hline \multicolumn{7}{|c|}{ I. Standar-Standar } \\
\hline \multicolumn{2}{|c|}{ Standar Keras } & 1 & 2 & 3 & 4 & 5 \\
\hline 1 & Hasil ujian yang memuaskan dan kesuksesan pelajar & & & & & \\
\hline 2 & Tingkat kemajuan tinggi & & & & & \\
\hline 3 & Penggunaan sumber daya-sumber daya yang efektif & & & & & \\
\hline 4 & $\begin{array}{l}\text { Umpan balik komunitas dan pelajar didasarkan pada } \\
\text { koleksi data yang sistematis }\end{array}$ & & & & & \\
\hline 5 & Kontrol dana yang efektif & & & & & \\
\hline \multicolumn{2}{|c|}{ Standar lunak } & 1 & 2 & 3 & 4 & 5 \\
\hline 1 & Suasana yang menyenangkan & & & & & \\
\hline 2 & Kesejahteraan pelajar merupakan prioritas & & & & & \\
\hline 3 & Layanan pelanggan terbukti secara nyata & & & & & \\
\hline 4 & Lingkungan yang bersahabat & & & & & \\
\hline 5 & Komitmen terhadap pelajar dengan semua keahlian & & & & & \\
\hline \multicolumn{2}{|c|}{ Aplikasi standar yang benar } & 1 & 2 & 3 & 4 & 5 \\
\hline 1 & $\begin{array}{l}\text { Institusi tidak mengukur dirinya hanya dengan } \\
\text { prioritas keras semata }\end{array}$ & & & & & \\
\hline
\end{tabular}




\section{Jaminana Mutu atau Quality}

\section{Assurance}

Sekolah merupakan organisasi atau wadah terstruktur dimana sekolah menengah dikelola secara formal dan berkesinambungan. Dengan demikian, sekolah menengah adalah dalam arti sekolah rnenengah yang dikelolanya dan mutu sekolah menengah adalah mutu pendidikan yang dikelolanya.

Dan segi proses pendidikan dapat dipandang sebagai industri jasa, jasa pendidikan dihasilkan oleh proses pendidikan, dengan pengertian ini keberhasilan pendidikan merupakan tingkat kemampuannya menghasilkan lulusan yang sesuai dengan kebutuhan dunia kerja.

Sêkolah Menengah dikatakan bermutu, jika. lulusan yang dihasilkan dapat memnenuhi harapan orang tua / siswa yang dikernukakan tadi. Edward Sallis mengemukakan pelanggan pendidikan tinggi adalah :

a. pelanggan primer adalah penerima dan pengguna layanan Iangsung sekolah menengah yaitu siswa,

b. pelanggan sekunder adalah pihak yang berkepentingan atas layanan sekolah menengah walaupun tidak menerima atau mempergunakan secara Iangsung yaitu orang tua siswa, pemerintah, sponsor dan

c. pelanggan tersier yaitu pihak yang menerirna dan mempergunakan lulusan sekolah rnenengah secara tidak langsung yaitu dunia kerja.

Ciri-ciri pokok mutti lulusan yang dibutuhkan siswa/orang tua, tcrmasuk yang dikemukakan oleh Tenner dan De Toro bahwa:

a. Reliability (keterpercayaan): Sesuai yang dijanjikan, jujur, aman, tepat waktu, keterscdiaan. 
b. Assurance (kctcrjaminan): Kompetcnsi (pengetahuan dan keterampilan), percaya diri, menimbulkan keyakinan dan kebenaran.

c. Tangibles (penampilan): Kebersihan, baik, teratur \& rapi, harmonis, indah.

d. Emphathy (Kepemerhatian): Penuh perhatian terhadap siswa. Cepat rnernberilan respon terhadap kebutuhan siswa (aspirasi) siswa, cepat memperhatikan keluhan siswa dan mengatasinya.

e. Responsiveness (Ketanggapan) : tanggap terhadap kebutuhan siswa, cepat memberi responsi terhadap permintaan siswa, cepat memperhatikan dan mengatasi keluhan-keluhan siswa.

Dalam TQM perhatian terhadap pelanggan menjadi unsur yang penting. Artinya pelanggan merasa puas atas produk sekolah dengan standar sebagaimana yang diinginkannya.

Menstandarisasi secara tepat aspek-aspek proses belajar mengajar merupakan pekerjaan yang tidak mudah mengingat keanekaragaman dalam pendidikan. Namun demikian usaha-usaha menentukan standar mutu dalam pendidikan perlu dilaksanakan terus.

Penggunaan istilah mutu dan standar sangat berimplikasi pada jaminan mutu. Untuk mengukur mutu perlu ada standar mutu. Yang dimaksud dengan standar mutu adalah paduan sifat-sifat barang atau jasa yang relatif mantap dan sesuai dergan kebutuhan pelanggan yang luas (lokal, nasional, global). Mutu suatu barang atau jasa dikatakan baik, jika sesuai dengan standar mutu yang ditentukan, yang berarti mernenuhi kebutuhan siswa. Dikenal ada bermacam-macarn standar tentang sistem mutu yang telah dikembangkan yang pada hakekatnya bertujuan untuk meningkatkan mutu dalam rangka memberikan kepuasan bagi siswa. 
Dengan demikian mutu pendidikan memberikan implikasi terhadap kepuasan konsumen. yang pada akhirnya berpengaruh terhadap akuntabilitas publik terhadap keberadaan lembaga pendidikan, artinya masyarakat semakin menaruh perhatian terhadap lembaga pendidikan tersebut.

\section{Unsur Mutu Pendidikan}

Unsur mutu dapat dibedakan atas dua kategori, terukur dan tidak terukur. Contoh unsur mutu yang terukur dalam pendidikan adalah jumlah tamatan, nilai ujian nasional, IQ calon siswa, dan lain sebagainya. Contoh unsur mutu pendidikan yang tidak terukur antara lain; disiplin siswa, keterampilan tamatan, dan lain sebagainya.

Selain itu, Adiviso (1998: 2) mengemukakan bahwa mutu memiliki karakteristik yang dapat dikelompokkan atas: fungsional, teknis, dann psikologis. Contoh ketiga karakteristik mutu tersebut dalam konteks pendidikan adalah:

- Karakteristik Fungsional : Relevansi isi pebelajaran dengan tuntutan dunia kerja

- Karaktenistik Teknis : Ketersediaan media pendidikan dan sarana lainnya.

- Karakteristik Psikologis : Reputasi lembaga pendidikan

\section{Sumber-sumber Mutu Pendidikan}

Patki (1998) mengidentifikasi adanya 13 sumber mutu dalam konteks penyelenggaraan pendidikan yaitu:

a. Guru yang bermutu prima

b. Hasil ujian yang sempurna

c. Kekhususan layanan

d. Laboratorium dan bengkel yang lengkap 
e. Bangunan yang dirawat dengan baik

f. Nilai moral yang tinggi

g. Ketersediaan sumberdaya yang mencukupi kebutuhan

h. Adanya dukungan orangtua siswa dan dunia usaha dan dunia industri

i. Penggunaan teknologi yang mutakhir

j. Kepemimpinan yang kuat dan sesuai dengan kebutuhan lembaga

k. Kepedulian dan perhatian terhadap siswa

1. Kurikulum yang memuat kebutuhan yang seimbang

m. Tim kerja yang baik

\section{Pelanggan Pendidikan}

Telah disinggung di depan bahwa salah satu prinsip TQM adalah fokus kepada pelanggan baik internal maupun eksternal. Sebagai pelanggan eksternal lembaga pendidikan utamanya adalah siswa, kedua adalah orangtua siswa, dan ketiga adalah pemerintah, masyarakat dan bursa tenaga kerja. Adapun pelanggan internal lembaga pendidikan adalah guru dan staf (Sallis: 70). Satu hal yang perlu dicatat, bahwa pelanggan internal memegang peran penting dalam dalam memberikan jasa yang bermutu bagi pelanggan eksternal. Oleh sebab itu, pengelolaan pelanggan eksternal sama pentingnya dengan pengelolaan pelanggan eksternal. Justru hal ini pula yang selalu dilupakan oleh para pemimpim organisasi termasuk lembaga pendidikan.

\section{Strategi Utama Penerapan}

\section{TQM Dalam Sistem Pendidikan}

Penerapan Standar Mutu Terhadap Setiap Sub-sistem

Sebagai sistem pendidikan terdiri dari sejumlah sub-sistem yang terkait dan secara bersama-sama dan sinergis bekerja untuk mencapai 
satu tujuan yaitu menghasilkan keluaran pendidikan yang berkualitas. Subsistem pendidikan ini dapat dikelompokkan atas:

Raw Input: atau masukan mentah yaitu siswa. Siswa merupakan sub-sistem yang akan diproses menjadi keluaran pendidikan.

Instrumental Input: atau masukan pranata yang diperlukan untuk menggerakkan proses pendidikan. Termasuk ke dalam kelompok ini adalah; kurikulum, guru, bahan ajar, peralatan, dan lain sebagainya.

Environmental Input: yaitu masukan lingkungan yang mempengaruhi jalannya proses pendidikan secara tidak langsung. Termasuk rnasukan lingkungan adalah berbagai kebijakan yang menjadi rujukan dan mempengaruhi penyelenggaraan pendidikan. Masukan lingkungan ini dapat dibedakan pula atas lingkungan internal dan eksternal. Masukan lingkungan internal berasal dan lembaga pendidikan yang bersangkutan termasuk iklim kerja dan kepmimpinan kepala sekolah. Masukan lingkungan eksternal berasal dan luar lembaga pendidikan misalnya undang-undang sisdiknas, undangundang guru dan dosen, perkembangan pasar kerja, dan lain sebagainya.

Proses: yaitu kegiatan pendidikan terutama belajar dan pembelajaran yang diselenggarakan oleh lembaga pendidikan yang bersangkutan.

Keluaran: atau output yaitu tamatan yang merupakan hasil proses pendidikan yang diselenggarakan oleh lembaga pendidikan yang bersangkutan.

Bagaimanapun hanya mutu yang akan melahirkan mutu. Oleh sebab itu, mengikuti berbagai prinsip dan konsep dasar yang telah dibahas sebelunmya maka untuk menerapkan TQM dalam penyelenggaraan pendidikan, harus diupayakan agar semua sub-sistem 
pendidikan memenuhi standar mutu yang telah ditetapkan seperti diilustrasikan dalam Gambar 2.

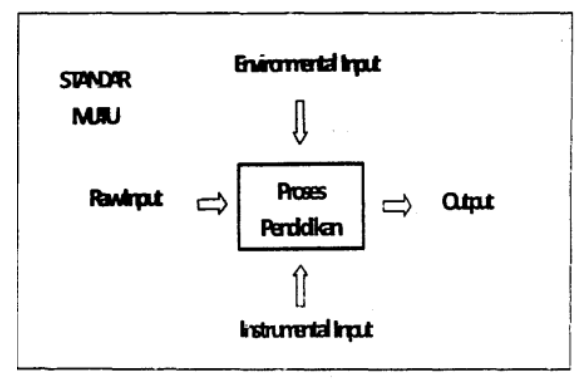

Gambar 2:

Strategi Utama Penerapan TQM Dalam Sistem Pendidikan

Peningkatan Berkelanjutan

Peningkatan berkelanjutan atau Continuous Improvement perlu dilakukan mengingat perubahan lingkungan termasuk tuntutan pelanggan. Untuk itu dapat dilakukan langkah-langkah berikut ini secara terus menerus:

Plan : merencanakan

Do : menerapkan

Check : menilai

Action : menindaklanjuti hasil penilaian

Dengan penerapan keempat langkah tersebut yang biasa dikenal dengan akronim PDCA secara terus menerus, dapat dilakukan perbaikan dan peningkatan secara berkelanjutan dan satu standar kualitas ke standar kualitas yang lebih tinggi seperti dapat dilihat pada Gambar 3. Dengan demikian tidak terjadi keusangan sistem karena semua sub-sistem dan standar senantiasa dikelola sesuai dengan perkembangan lingkungan strategisnya. 


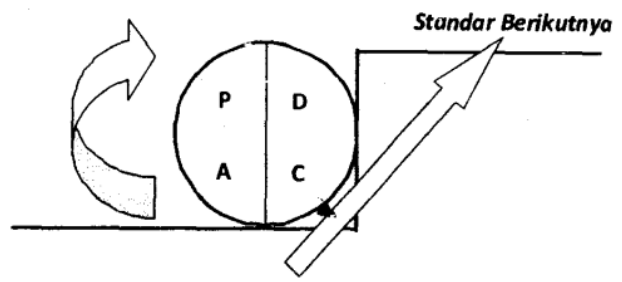

Gambar 3:

Aplikasi PDCA Untuk

Peningkatan Tersus Menerus

\section{Alat dan Teknik TQM}

Ada sejumlah peralatan dan teknik manajemen atau management tools yang biasa digunakan dalam penerapan TQM.

Peralatan tersebut di antaranya:

a. Brainstorming

b. SWOT Analysis

c. Cause and Effect Diagram atau disebut juga Fishbone Diagram

d. Quality Circle dan Focus Team

e. Nominal Group Technique

f. Raddar Chart

g. Pareto Chart

h. Strategic Planning

Alat dan teknik manajemen tersebut digunakan secara sendirisendiri dan gabungan dalam mengelola mutu baik yang terkait dengan masukan, proses, maupun keluaran.

\section{Penyebab Kegagalan TQM}

Setidaknya ada 10 kemungkinan penyebab kegagalan penerapan TQM termasuk dalam sistem pendidikan (Patki: 10) yaitu:

a. Kurang sempurnanya perencanaan 
b. Pimpinan puncak tidak memimpin langsung upaya penerapannya

c. Manajer tingkat memengah tidak terlibat sejak awal

d. Lemahhnya komunikasi antar unsur terkait

e. Kurangnya kepedulian terhadap pelanggan

f. Tidak efektif dan kurang memadainya pelatihan SDM

g. Terlalu tingginya harapan yang akan dicapai untuk waktu yang singkat

h. Berlanjutnya budaya berbasis "takut akan perubahan"

i. Penerapan dianggap sebagai tujuan daripada sebagai alat pencapaian tujuan.

j. Upaya peningkatan mutu tidak diintergrasikan ke dalam kerja nyata lembaga.

Kesepuluh penyebab kegagalan tersebut dapat muncul secara sendiri-sendiri dan dalam waktu terpisah, tetapi dapat beberapa penyebab muncul bersamaan dalam waktu yang sama. Semakin banyak penyebab kegagalan yang muncul bersamaan, semakin kompleks metoda yang diperlukan untuk mengatasinya. Selain itu, diperlukan pula kecermatan dan ketekunan serta kerjasama sinergis dari semua pihak terkait.

\section{Kesimpulan}

Dari uraian di depan dapat ditarik sejumlah kesimpulan dan diajukan saran- saran yang dapat dijadikan rujukan dalam mengimplementasikan TQM dalam mengelola satuan pendidikan.

1.TQM adalah pendekatan manajemen yang sangat efektif dan efisien dalam mencapai tujuan lembaga termasuk lembaga pendidikan dibandingkan dengan manajemen dengan pendekatan tradisional. Keunggulan TQM ini setidaknya dicapai karena karena 3 (tiga) hal. 
Pertama, pendekatan ini berfokus pada kebutuhan pelanggan yang justru merupakan sarana penghubung antara kedua pihak berkepentingan; lembaga dan pelanggan. Pelanggan itu sendiri merupakan faktor utama yang menentukan eksistensi lembaga. Kedua, TQM mengelola mutu sejak awal hingga proses produksi sehingga pemborosan dan penyimpangan dapat ditekan sedini mungkin. Ketiga, TQM mendorong terbangunnya nuansa kekeluargaan diantara lembaga dan pelanggan baik internal maupun eksternal sehingga semua berusaha berkontribusi secara antusias dalam mendukung tercapainya produk dan jasa sebagai alat pemenuhan kepuasan mua pihak; lembaga, karyawan, danpelanggan eksternal. Dengan nuansa ini maka keberhasilan lembaga dalarn memenuhi kebutuhan pelanggan akan mutu merupakan obsesi semua pihak.

2. Penerapan di industri dan organisasi non-kependidikan lainnya telah menunjukkan bukti nyata keampuhan TQM dalam meningkatkan kepercayaan pelanggan terhadap produk dan jasa. Kepercayaan ini telah mendukung eksistensi berbagai organisasi dalam jangka panjang termasuk memenangkan persaingan yang semakin ketat dan krusial. Oleh sebab itu, adalah cukup beralasan jika lembaga pendidikan di Indonesia menerapkan TQM dalam sistem manajemennya. Alasan tersebut semakin kuat ketika akhir-akhir ini tekanan persaingan diantara sekolah baik sekolah nasional maupun sekolah internasional yang beroperasi di Indonesia semakin keras. Banyak bukti yang menunjukkan bahwa sekolah yang berdiri sejak beberapa dekade yang lalu tetapi tidak peduli kepada mutu dan pelanggan akhirnya tidak dapat bertahan. Sebaliknya, sejumlah sekolah pendatang baru yang sangat memperhatikan mutu dan kebutuhan pelanggan justru menjadi 
sekolah favonit yang setiap tahunnya kelebihan peminat dibandingkan daya tampungnya.

3. Pemerintah telah menginisiasi penerapan TQM ke dalam sistem tatakelola satuan pendidikan nasional untuk semua jenjang pendidikan dan semua status sekolah. ini terbukti dan diluncurkannnya program BOMM atau Bantuan Operasional Manajemen Mutu kepada sekolah. Namun masih banyak sekolah yang kurang berhasil sebagaimana diharapkan. ini diantaranya tercermin dan masih rendahnya capaian siswa dalam Ujian Nasional, masih belum diterapkannya PAKEM dalam belajar dan pernbelajaran di kelas yang dilaksanakan oleh sebagian besar guru, dan keberhasilan tamatan mengisi kesempatan kerja yang ditawarkan oleh dunia kerja terutama di pasar kerja intemasional. Ketidakberhasilan ini diantaranya disebabkan oleh promosi kepala sekolah yang di beberapa kasus tidak berbasis kompetensi tetapi dipengaruhi oleh pertimbangan politis yang dalam beberapa hal tidak kondusif dalam penciptaan kultur mutu. Selain itu, sebagian kepala sekolah belum pernah mengikuti diklat khusus calon kepala sekolah sehingga belum memiliki kompetensi yang cukup dalam penerapan TQM di sekolahnya. 


\section{DAFTAR PUSTAKA}

Adviso, B.F. 1998. Basic Ideas Behind Total Quality Management. Manila Colombo Plan Staff College for Technicion Education

Arcaro, Jorome S. 2006. Pendidikan Berbasis Mutu : Prinsip-prinsip Perumusan dan Tata Langkah Penerapan. Yogyakarta: Pustaka Pelajar.

Bloom. BS. 1963. Taxonomi Of Educational Objectives The Clas/Icational Goal. Hand Books I. Cognitive Domain. (London: Longman Green \& Co. Ltd., 1971).

David J. Fax, Research Proccess in Education, (New York: 1-bit, Rinehart and Winston, inc., 1969)

Edward, Sallis li., Total Quality Management in Educational. (London : Kogam Page Ltd., 1993).

Faangen. 1985. A Psychoeducational Curriculum Approach to Teaching Self Control Behavior Disorders, Prestice Hall Upper Saddle.

Gasperz, Vicent (Ed.) (2001) : Total Quality Management, Gramedia Pustaka Utama. Jakarta.

Juran M. Juran. 1982. Leadership for Quality, (USA: Juran Institute Macmilan, Inc)

Linder, Jane C. 2004. Qutsourcing for Radical Change: A Blod Approarch to Enterprise Transformation. New York : American Management Assocation.

Tenner, Arthur R. and De' Toro Irving, J., Total Quality Management: three Steps to Continous Improvement. (Maddison: Wesley Publishing Company, 1992).

Patki, SD. 1998. Process of Implementing TQM, Manila: Colombo Plan Staff College for Technicion Education. 